\title{
A university post-entry English language assessment: Charting the changes
}

\author{
JOHN READ \& JANET VON RANDOW* \\ University of Auckland, New Zealand
}

Received: 19 July 2013 / Accepted: 17 September 2013

\begin{abstract}
The increasingly diverse language backgrounds of their students are creating new challenges for Englishmedium universities. One response in Australian and New Zealand institutions has been to introduce post-entry language assessment (PELA) to identify incoming students who need to enhance their academic language ability. One successful example of this type of programme is the Diagnostic English Language Needs Assessment (DELNA) at the University of Auckland, which has been implemented across the university since 2002. This paper discusses the reasons for introducing the assessment and outlines its current operation. As part of the validation process feedback is obtained from academic staff, and from students who have completed the assessment and been advised about their opportunities for enriching their academic literacy. The focus of this paper is on the ways the feedback has led to changes both in the composition and administration of the assessment and the delivery of effective English language programmes.
\end{abstract}

KEYWORDS: academic literacy, post-entry language assessment (PELA), diagnostic assessment, student evaluation, language enrichment

\section{RESUMEN}

La creciente diversidad lingüística de sus estudiantes está suponiendo nuevos retos para las universidades de habla inglesa. Una manera de afrontar esos retos por parte de las universidades australianas y neozelandesas ha sido la introducción de evaluación de lenguas post-ingreso para identificar a los alumnos que necesitan un refuerzo de sus habilidades en inglés académico. Un ejemplo es el programa Evaluación Diagnóstica de Necesidades en Lengua Inglesa de la Universidad de Auckland, que se implementa desde 2002. Este artículo presenta las razones para la introducción del programa y detalla su funcionamiento actual. Como parte del proceso de validación, se recopila retroalimentación del personal académico y de estudiantes que han pasado por esa evaluación post-ingreso y a los que se les ha aconsejado sobre las oportunidades existentes para la mejora de sus habilidades académicas en inglés. El artículo, pues, se centra en explicar cómo dicha retroalimentación ha contribuido, por una parte, a la realización de una serie de cambios tanto en la composición como en la administración de la citada evaluación y, por otra, al desarrollo e implementación de programas de refuerzo en lengua inglesa.

PALABRAS CLAVE: alfabetización académica, evaluación de lenguas post-ingreso, evaluación diagnóstica, evaluación por parte de los estudiantes, enriquecimiento lingüístico

\footnotetext{
*Address for correspondence: Associate Prof. J. Read. Department of Applied Language Studies and Linguistics, University of Auckland, Private Bag 92019, Auckland 1132, New Zealand. Email: ja.read@auckland.ac.nz. Prof. J. von Randow. Diagnostic English Language Needs Assessment (DELNA). University of Auckland, Auckland, New Zealand. Email: j.vonrandow@auckland.ac.nz
} 


\section{INTRODUCTION}

English-medium universities in many countries are facing new challenges resulting from the increasingly diverse language backgrounds of their incoming students. Until recently, the focus has been on international students entering universities in the major English-speaking countries, particularly the United States, the United Kingdom and Australia. These students normally need to obtain a minimum score on one of the recognised international proficiency tests as a requirement for admission, and may subsequently take a placement test to determine which (if any) courses in academic writing or other language skills they should enroll in once they arrive at their university. Tertiary institutions in Europe, East Asia, the Middle East and elsewhere are also introducing degree programmes taught through the medium of English and are facing the same question of how to ensure that the students have adequate proficiency in English to be able to cope with the language demands of their studies. However, there is growing recognition that the need for an enhanced level of academic language proficiency is not confined to international students but applies to many domestic students in the countries concerned as well. The successful completion of secondary school qualifications may not provide sufficient evidence that matriculating students have the necessary level of language proficiency or academic literacy to ensure adequate achievement in their university studies.

In Australia this has given rise to a distinct form of assessment with its own acronym PELA: post-entry (English) language assessment (Read, forthcoming). The purpose of a PELA is to identify, from among the students who have already been admitted to the university, those who are likely to have significant academic language needs, in order to guide or direct them to appropriate learning resources on campus. Some Australian universities such as Sydney (Bonanno \& Jones, 2007) and Melbourne (Ransom, 2009) have offered this form of assessment since the early 1990s, but public concern about English language standards in the universities (see, e.g., Birrell, 2006) has led to similar initiatives in numerous other institutions in the country in more recent years. The trend was reinforced by the adoption of the Good Practice Principles for English Language Proficiency for International Students in Australian Universities (AUQA, 2009) by the academic audit agency of the Australian Government. A new audit body established in 2012, the Tertiary Education Quality and Standards Agency (TEQSA), announced that the auditors would review closely how well Australian universities were promoting high English language standards for all their students (Lane, 2012). The most relevant principle for our purposes here states that “Students' English language development needs are diagnosed early in their studies and addressed, with ongoing opportunities for self-assessment” (AUQA, 2009:4).

A distinctive feature of post-entry assessments is that they are generally projects undertaken by individual institutions to address the perceived needs of their student population in relation to language proficiency or academic literacy. Often the initiative has come from student learning advisers rather than specialists in English for Academic Purposes 
or language assessment. This means that the assessments take diverse forms and vary in their implementation, according to whether they are intended for all students or just for international students; whether they are implemented in particular academic programmes or across the institution; whether participation in the assessment is required or recommended; and so on. A national survey by Dunworth (2009) is the most complete published account of Australian university PELAs, and it has recently been complemented by a website www.degreesofproficiency.aall.org.au - which provides not only a database of existing assessments but also resources to assist institutions in designing programmes to enhance their students’ English language proficiency.

One particularly comprehensive and successful post-entry assessment is found not in an Australian university, but at the University of Auckland in New Zealand, which introduced the Diagnostic English Language Needs Assessment (DELNA) programme in 2002 and has since extended it to cover all first-year undergraduate students, as well as incoming doctoral candidates. The design and implementation of DELNA have been dealt with extensively elsewhere (see Elder \& von Randow, 2008; Read, 2008; Read, forthcoming). Here we will focus on the ways in which the assessment programme has been adapted over the last ten years in response to feedback from academic staff and students. This can be seen as part of the ongoing process of validating the assessment (Davies \& Elder, 2005) to ensure that its primary objectives are being achieved.

\section{BACKGROUND}

The motivation for introducing DELNA at Auckland came not from external pressures but from concern in the 1990s among teaching staff within the university that a lack of academic language proficiency was contributing to higher student failure rates (Ellis \& Hattie, 1999; Moran, 1995). Over a period of 30 years the student population had become increasingly multilingual, as a result of not only vigorous efforts to recruit international students but also an influx of young people from recently established immigrant communities in Auckland. Adding to the mix of students with academic literacy needs were mature adults who were eligible for special admission, and students from the Maori and Pasifika ethnic communities being recruited on equity grounds. Since there were legal constraints on requiring some groups of domestic students but not others to take a language assessment (see Read, 2008, for further detail), the decision was made to develop DELNA as an assessment procedure that could be administered to all students, regardless of their language background, although initially it was targeted at academic programmes with a high percentage of students for whom English was an additional language (EAL).

By funding DELNA the University acknowledged its responsibility to ensure that students admitted with significant language or literacy needs would be identified and given 
the opportunity to enhance what the University's Graduate Profiles describe as the "ability to access, identify, organise and communicate knowledge effectively in both written and spoken English....”. It was also expected that students would share this responsibility by taking DELNA (without cost to themselves) and acting on the language advice given.

We will describe in some detail below how DELNA has developed over the last ten years in response to feedback from university staff and students. However, it is useful at this point to orient the reader by giving an overview of how the programme currently operates, now that it has been fully implemented. As shown in Figure 1, the assessment is conducted in two phases. The Screening, which is administered online in computer labs on campus, is designed to provide an efficient basis for exempting students whose English language proficiency is unlikely to cause any concern. It comprises an academic vocabulary test and a speeded reading task (known in the literature as the cloze-elide procedure - see Davies, 1990; Manning 1987). The setting of the cut scores for the Screening phase is discussed in depth by Elder and von Randow (2008).

Those students whose Screening result falls below the minimum cut score then proceed to the Diagnosis phase, which takes two hours and includes paper-based Listening, Reading and Writing tasks of the kind commonly found in tests of English for Academic Purposes. A low score for the Diagnosis, roughly equivalent to a band score of 6.5 or below in the International English Language Testing System (IELTS), means that the student is scheduled to have an individual consultation with a DELNA language adviser, who reviews the assessment results and informs the student about the options available for academic language enrichment. In some degree programmes, the students are required to follow this advice, but otherwise it is up to them to take advantage of these opportunities or not.

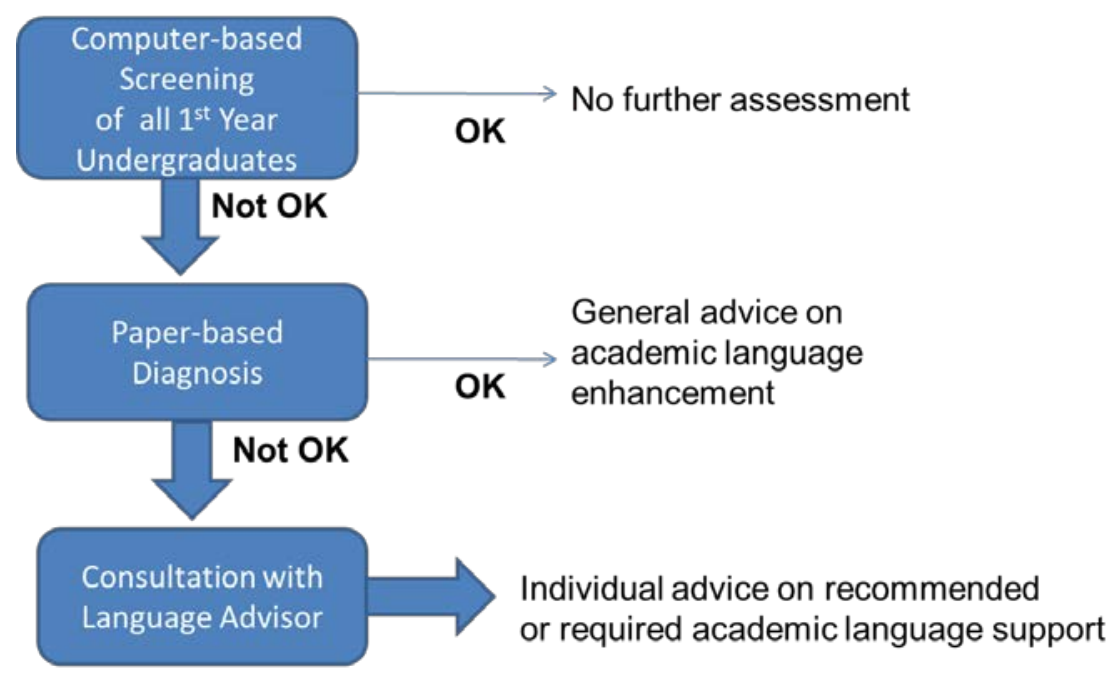

Figure 1: Overview of the DELNA process 


\section{VALIDATION PROCEDURES}

Although a post-entry assessment such as DELNA is considered to involve relatively low stakes for the students, it is still important that it should provide accurate information about their academic language proficiency so that, on the one hand, proficient students are not assessed more than is necessary and, on the other, those who are at most need of enhancing their academic language skills are correctly identified. The DELNA programme has had a strong commitment to validation research, beginning with the initial trial (Elder \& Erlam, 2001) conducted in 2001, before the assessment became operational, and the pilot study the following year (Elder \& von Randow, 2002). Subsequently there have been published studies on native vs. non-native speaker performance on the assessment (Elder, McNamara \& Congdon, 2003), the training of writing raters (Elder, Barkhuizen, Knoch \& von Randow, 2007; Elder, Knoch, Barkhuizen \& von Randow, 2005; Knoch, Read \& von Randow, 2007), the development of the rating scale for writing (Knoch, 2009), and the utility of the Screening tool (Elder \& von Randow, 2008), as well as numerous conference presentations on the impact of the assessment, particularly on students. It is this last aspect of validation that we take up in the present article.

In language testing, test-taker perceptions of a test have traditionally been regarded somewhat dismissively as providing evidence just for the "face validity" of the instrument (see, e.g. Bachman, 1990; Lado, 1961). However, several authors have acknowledged that a test should be acceptable to the candidates and other stakeholders (Alderson, Clapham \& Wall, 1995; Carroll, 1980) as a suitable measure of the relevant language abilities, or that it should have “test appeal” (Bachman \& Palmer, 1996; Davies et al., 1999).

Following Read and Chapelle (2001), Read (2008) applied the concept of "test presentation" to DELNA and discussed in some detail the various steps that have been taken to promote the acceptability of the assessment among students, staff and administrators at the University. This was particularly important in the early years, when to a significant degree students were encouraged rather than compelled to take the assessment. Even now, when the Screening is a requirement for all first-year students, the DELNA staff make ongoing efforts to present the assessment in a positive light, so that its purpose is clearly understood and the students engage with the assessment tasks in a manner that will produce a valid measure of their academic language ability.

In order to ensure that these efforts are successful, it is necessary to obtain regular feedback from students. Since its inception, students who have completed the DELNA Diagnosis and received language advice have been sent an online questionnaire, which they are invited to complete anonymously. The questionnaire offers them the chance to comment on DELNA, on how their English language skills have affected their university experience and on any language enrichment they have accessed or are planning to access. Respondents are also given the opportunity to provide contact details if they would like to discuss these 
issues in more depth and are willing to take part in a follow-up interview. Over the last 11 years the response rate to the questionnaire has been approximately $22 \%$, and so the respondents are a self-selected group who are not representative of the whole DELNA candidature. The same applies to the small number of students who participate in the interviews each semester. Nevertheless, the responses have given invaluable feedback that has brought about the numerous changes to the DELNA programme which we discuss below.

For this article, we have drawn on responses from 2000 online questionnaires, together with the transcripts of 20 interviews. We are in process of undertaking a comprehensive analysis of the data for another paper (in preparation). Thus, we will not present a systematic report on the findings here, but rather use quotations and other data to support a descriptive account of how the assessment programme has developed in response to student comments.

A more informal source of feedback has been phone calls and emails to the DELNA Office, particularly from students who were upset, angry or confused about the assessment programme.

Formal feedback from staff comes through the DELNA Reference Group, chaired by the Deputy Vice Chancellor (Academic) and including representatives of all faculties, the units providing learning support services for students, the International Office, the School of Graduate Studies and the Admissions Office. Its role is to monitor the administration of DELNA and to facilitate communications between the DELNA office and the wider university. Other sources of feedback are conversations with and emails from administrative staff and from academic staff, particularly those coordinating first-year courses.

\section{CHANGES TO THE ASSESSMENT}

\subsection{Initial changes to the assessment format}

In its original trial version in 2001, the DELNA assessment consisted of the current five tasks, plus a longer 55 minute writing task. In January 2002, before the beginning of the university year, a group of students whose enrolment forms showed no evidence of an English language qualification were identified by the University's Admissions Office and invited by letter to complete these six tasks. They were told that they would then be advised about the language enrichment they should access as they began their studies.

Students who scored above a certain threshold on the first two tasks, academic vocabulary and text editing, were deemed to have appropriate language skills for university study; this was conveyed to them by email and their other tasks were not marked. Those who reached the threshold after the short writing was marked were also emailed with this result. On the other hand, students under the threshold on the first three tasks had the final three tasks marked and were then sent an email advising them of the appropriate language enrichment options available for them on campus. There was immediate feedback from the students by 
email or phone that the assessment was too long, and that they wanted the results of all six tasks. After this feedback the number of tasks they were asked to do was reduced and all results were sent.

\subsection{Adapting the diagnostic tasks}

In March 2002 the pilot administration of DELNA was conducted in class in first-year courses in academic units which had large enrolments of students with English as an additional language (EAL): the Faculties of Business and Economics, Architecture, Property, Planning and Fine Arts (APPFA), and Theology; the School of Pharmacy; and the Department of Film, Television and Media Studies (FTVMS). An immediate problem arose, however, as the listening, reading and long writing tasks required more administration time than the two-hour lecture slot allowed, creating an obvious difficulty that staff and students were not slow to report. This problem was solved by replacing the longer 55-minute writing task with the shorter 30-minute one. The shorter task was then rated analytically rather than holistically, and follow-up research demonstrated that it was a valid measure for diagnostic purposes (Davies \& Elder 2005, Elder \& von Randow, 2002).

In 2003 and in Semester 1, 2004, DELNA was administered in first-year courses from other faculties. At this point the two-hour Diagnosis, consisting of the listening, reading and short writing tasks, was the preferred format for all candidates. However, in their postDELNA evaluations, students from English-speaking backgrounds complained that such a lengthy assessment was a waste of their time:

This test should really be only for those that have English as a 2nd or 3rd language not for those who are already proficient in either spoken or written as it is a waste of time. (2003)

\subsection{Creating the online screening tool}

The DELNA team responded to the feedback by developing the first two tasks - academic vocabulary (7 minutes) and text-editing (10 minutes) - as a web-based Screening measure, which could be an efficient and cost-effective means to exempt proficient English users from the longer Diagnosis. Administering the Screening in computer labs across the campus required only invigilator costs, at approximately $\$ 1$ a student. The Diagnosis, on the other hand, which involved additional amounts for printing, a longer period of invigilation and rating of scripts, cost about $\$ 27$ a student.

This change proved critical to DELNA's wider acceptance across the University, and the Screening was subsequently taken up by more faculties and by more students who had not been specifically requested to do it. As Read (2008) points out, students from Englishspeaking backgrounds were quite intrigued by the online assessment because it was novel for them. As shown in Table 1, the impact was a dramatic increase in the numbers of students 
taking the Screening, which meant that DELNA was able to identify more students who could be at risk because of limited academic English ability. A corresponding drop in the number of candidates for the Diagnosis phase helped to keep the DELNA programme budget in balance.

\begin{tabular}{lrrrr}
\hline 2002 & 2003 & 2004 & 2005 & \\
\cline { 3 - 5 } & & & & \\
Screening & 245 & 139 & 2525 & 3964 \\
Diagnosis & 1111 & 1904 & 2500 & 1120 \\
\hline
\end{tabular}

Table 1. Numbers of students taking DELNA by year, 2002-2005

At the end of 2004, although some academic programmes would have preferred to continue administering the two-hour Diagnosis to all their first-year students, the DELNA Reference Group agreed to implement fully the two-phase structure of the assessment outlined in Figure 1, in the interests of cost-effectiveness. From that point on, about threequarters of DELNA candidates have taken only the Screening.

A further development occurred in 2005, when the Deputy Vice-Chancellor (Academic), who has overall management responsibility for the DELNA programme, asked the deans of all faculties to make the Screening a requirement for all first-year students. By 2009 the University audit report stated that DELNA was now mandatory for these students (The University of Auckland Academic Audit, 2009, p. 31). As shown in Table 2, this has further boosted the number of candidates for the Screening in recent years, so that by 2012 it was estimated that more than $90 \%$ of first-year undergraduates participated.

\begin{tabular}{|c|c|c|c|c|c|c|}
\hline 2006 & 2007 & 2008 & 2009 & 2010 & 2011 & 2012 \\
\hline Screening & 5487 & 5602 & 5681 & 6713 & 7190 & 7543 \\
\hline Diagnosis & 718 & 708 & 965 & 1500 & 1148 & 1199 \\
\hline
\end{tabular}

Table 2. Numbers of students taking DELNA by year, 2006-2012

Although the numbers of students taking the Diagnosis have also increased, the 1353 who participated in 2012 represent only about $60 \%$ of those who were recommended to do so, based on their Screening result. Faculties vary in the extent to which they require their students to complete the Diagnosis, and many students avoid going on to the second phase of the assessment if they can. Analyses of the academic records of these "avoiders" show that the majority have grade point averages (GPAs) at the end of their first year at the low end of the scale. 


\subsection{Reporting the DELNA results}

One advantage of introducing the online Screening was that students could be sent their results almost immediately. These were originally reported as raw scores but, as more forms of the tasks were developed with slightly different cut scores, the results were classified into three categories for reporting purposes:

- Good: language skills appropriate for university study

- Satisfactory: language skills adequate but the student is informed of language workshops available on campus

- Diagnosis required: the student is advised to book for the Diagnosis phase of DELNA.

Students accepted this change with little comment, and, at the present time, the very few students who ask for raw scores are given the number of correct items for each task. Those who believe their result may have been affected by a problem in the computer lab are encouraged to contact the DELNA Office so that their results can be reviewed and they can repeat the assessment.

In the case of the Diagnosis, the results are reported for the individual tasks and for the whole assessment as a band score from 9 to 4, as shown in Table 3 - although these descriptors are not included in the student's report. Those with an average DELNA band of 6.5 or above are sent their results profile by email, with advice on academic language enrichment as appropriate. Students with average below 6.5, or a writing band of 6 or below, are asked to make an appointment with a DELNA language adviser to review their score profile and discuss opportunities for language enrichment. As with participation in the Diagnosis, not all students come voluntarily to this appointment. Following the initial emailed invitation to make the appointment, a second email reminder is sent, then a phone call is made and finally, since 2011, a text message is sent from the University's Call Centre. Compliance reached $68 \%$ in 2012.

Bands 9 and 8

Band 7

Band 6

Bands 5 and 4
Expected to acquire academic literacy independently

Use of language enrichment opportunities recommended

Further language instruction recommended

At risk of failure: enrolment in an English language course strongly recommended

Table 3. DELNA Diagnosis Bands for Listening, Reading and Writing 


\section{ENGAGING THE STUDENTS}

\subsection{Changing the promotion material}

How best to present DELNA to the students has always been a major consideration (Read 2008). The assessment has never been referred to by DELNA staff as a "test" or an "exam", and the focus has been on the outcome: the language assistance available for those who needed it. While some students were quite happy with the process, others wanted more information about it.

I think if you let us know about the test, the type, and the content of the test, it will be easier for us to do the test properly. (2005)

In response to this kind of request, promotional material has been included in all Orientation packs and given out at the Courses and Careers Day for secondary school students prior to university enrolment. The originally rather formal posters and flyers were from 2004 replaced by more attractive promotional material. The advertising became more colourful; a photograph showed a multicultural group of students; the wording was changed so that the Screening was described as a "language health check"; and slogans such as DELNA will "get you off to a flying start as you begin your studies” were adopted.. The most recent posters and flyers also include a New Zealander of European descent in the foreground to emphasise the message that DELNA is for all first-year students, no matter what their language background, and many students have commended its inclusiveness.

In general, DELNA is a very good tool and worth of you to recommend its widespread use. (2010)

\subsection{Changes to the DELNA website}

The fact that DELNA is for all first-year students is further reiterated on the website (www.delna.auckland.ac.nz), which was updated in 2010.The students' page on the website provides all the necessary information about the assessment, together with a link to a 16-page handbook in pdf format. The handbook describes both phases of the assessment, with exemplars of each task, a detailed description of the rating procedures and an explanation what the DELNA bands mean. A link on the website takes students to the site for booking a DELNA session and also to the practice tasks for the Screening, so that all students have the opportunity to familiarise themselves with the tasks in advance. The booking site replaced the original procedure whereby assessment sessions for students in particular courses were scheduled by liaison with the teaching staff of the course. Students now have the opportunity to select from a schedule of DELNA sessions one which suits their personal timetable. Taking 
into account student feedback, the site was completely revamped in 2011, with the result that the number of calls to the DELNA office has decreased noticeably.

\subsection{Changes to the online Screening instructions}

When students begin the Screening, they are told to read the instructions on the screen and follow them carefully.

If I had read the instructions more carefully, rather than trying to get through in a rush, I would have had no problems answering all questions in the giving time. So, I think the instructions could have perhaps shown a bit more cautious attention. (2010)

The instructions have been revisited in the light of such comments. For example, information about the time for each task was enlarged and a red clock, rather than the original black one, now marks off the minutes in the corner of the screen. In spite of this, some students still report that they did not know the tasks were timed.

\section{POST-DELNA ADVISING}

\subsection{Appointing DELNA Language Advisers}

Obviously, it is also important that students should be adequately informed about the results of the DELNA assessment and what they mean in terms of any follow-up action that they should take. Originally the results and advice were sent in a brief email. Students, however, made it clear that they expected more than this:

Can you be more specific with the results?? i.e. what we need to improve on and what we did well. (2003)

The DELNA staff were concerned in particular about communicating with the students who were most at risk of poor academic achievement, as signalled by band scores of 4,5 or 6 in the Diagnosis. As noted above, this led to the appointment in 2005 of a DELNA Language Adviser, who could conduct individual advisory sessions of up to 30 minutes to go over each student's results and discuss them options for enhancing their academic language skills.

It is very helpful that the assessment is link with the learning support. (2010)

In order to be well informed about the options available, the Language Adviser established a network of contacts with student advisers and first-year course coordinators in all faculties, as well as tutors offering specialist support in the areas of English language enrichment, academic writing and study skills. Her work on the main City Campus was more 
recently complemented by advisers on the three satellite campuses where the Faculty of Education offers teacher education programmes. The student body in Education includes a large percentage of students who are mature and/or from ethnic minority backgrounds, and who are much more responsive to face-to-face contact in their own study environment.

I agree that this program should be running in all branches. I am at Manukau Campus. We need a tutor to do the test and be able to follow up those areas of weaknesses. (2009)

In Semester one a friend and I went to about 10 workshops on writing and other things - may not have done that without the DELNA experience and talking to Jenni, etc. The workshops were well attended certainly at the beginning. They were really worthwhile (2011).

\subsection{Students' response to language advice}

While there has been some debate in the Australian literature about the benefits and costeffectiveness of such language consultations (Arkoudis, Baik \& Richardson, 2012; Knoch, 2012; Murray, 2010), the students who have taken up the opportunity have responded overwhelmingly positively:

I took ESOL101 Academic English Writing paper last semester thanks to DELNA's help and advice. That was surely timely and appropriate guide for me. I received a great help through the class. (2005)

Some academic programmes, especially those leading to professional degrees, require their students to meet with the Language Adviser and follow the advice given; otherwise, students do so voluntarily. The number of students attending advisory sessions has continued to grow, as can be seen in Table 4. From 2011 the figures include students seen by advisers on the satellite campuses as well as the City Campus.

\begin{tabular}{lrrrrrrr}
\hline 2005 & 2006 & 2007 & 2008 & 2009 & 2010 & 2011 & 2012 \\
\hline 88 & 124 & 320 & 333 & 445 & 458 & 617 & 829
\end{tabular}

Table 4. Student appointments with a Language Adviser

In the online questionnaire which DELNA candidates complete at the end of their first semester of study, they are asked to give reasons for not making an appointment with the adviser or not following her advice. Figure 2 presents a compilation of the main reasons given over the last ten years. The single most common reason, amounting to about $46 \%$ of the responses, was a lack of time, and the somewhat related response that the student could not fit any language enrichment activities into their crowded course timetable accounted for another $15 \%$ of responses. A third category of response (about 11\%) was that the student did not 
know how to access opportunities to enhance their academic English ability, or in some cases that the facilities were too far away from their own campus. Other responses were too diverse to classify simply.

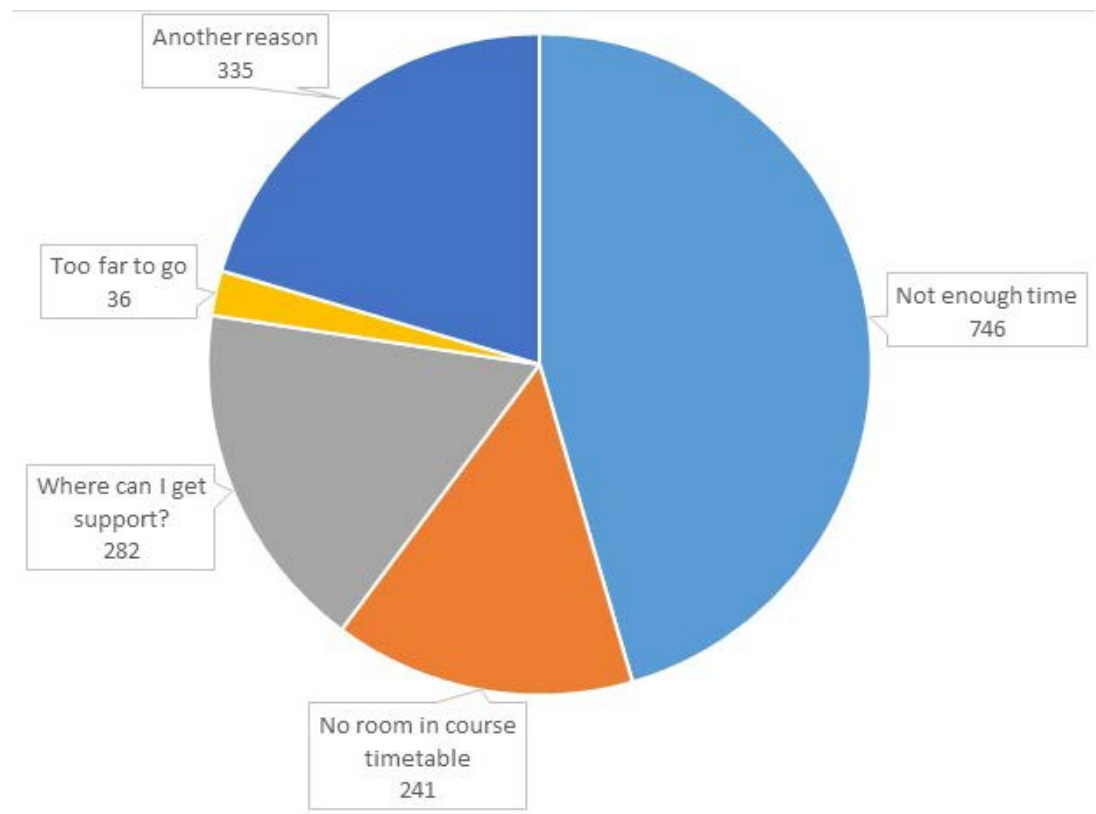

Figure 2. Questionnaire responses giving reasons for not doing extra English study after taking DELNA $(n=1600)$

\subsection{Compulsory uptake of Diagnosis and language advice}

It is easier for students to avoid participating in the post-Diagnosis phase of DELNA if it is not compulsory for them to do so. In the Australian context, Dunworth (2009: 8) reported that whether post-entry language assessment should be mandatory or optional - for all students or for those in targeted categories - is a matter of ongoing debate among university staff. According to Ransom (2009), a University of Melbourne Taskforce recommended compulsory assessment in their institution, on the basis that leaving it up to the students would not ensure that they obtained the language assistance they needed.

At Auckland, there has been a trend towards making the DELNA assessment and any necessary follow-up activity required, particularly for students in academic units which offer professional degrees: the Faculties of Engineering and Education, and the Schools of Nursing and Pharmacy. Here the concern is not just with the students' ability to cope with their academic studies but also whether they will meet the English language standard of the relevant professional registration body upon graduation. All of these programmes have designated language enrichment programmes and barriers in place to prevent students' progression through their degree course without complying with the DELNA requirement. The majority of these students have been responsive to the DELNA language advice and generally admit that they have problems with their English language proficiency. 
Yes, I think ENGGEN199 [a requirement for $1^{\text {st }}$ year Engineering students] was pretty helpful. I attended the workshop, which is 15 hours I think. I think it was pretty fun interacting with the teachers and they were professional and they got us to talk a lot and improve our English. (2012)

By contrast, the Faculty of Arts has generally not enforced their students’ participation, except in the case of those admitted on equity grounds: students of Maori and Pasifika ethnicity and those with a disability. Since 2009 such students have been required to take DELNA and, in their first semester, enrol in an English language credit course recommended by the DELNA Language Adviser. The feedback from these students suggests that they are grateful to be able to take such a course in the very beginning of their degree programme as this lays a good foundation for future study.

Yeah, I think it's very important, it's certainly been helpful to me, that is for sure, made me realize I need to learn how to write essays properly. (2011)

Since 2011 all new doctoral candidates have been included in the DELNA process. Evidence gathered by the School of Graduate Studies indicated that some of the challenges facing supervisors and their doctoral students had their roots in language difficulties and DELNA assessment was adopted as the first step in addressing the issue. Students scoring below Band 6 in the Diagnosis must act on the DELNA Adviser's recommendation as one of the requirements for successfully completing their first year of provisional registration as a doctoral candidate. In spite of the compulsion and the initial surprise expressed by international students who had already obtained the necessary IELTS score for admission, the fact that the University has language assistance in place is acknowledged by these highly motivated students.

Yes, it is very good. You know some other friends they come and they also need to take it and they are worried about it - I say it is easy - it is not an examination - they will give you lots of suggestions very good. Ah but you know, people are still a little worried about it. (2012)

\section{ADDRESSING LANGUAGE NEEDS}

\subsection{Acceptance of DELNA and language needs}

The majority of students responding to the questionnaire over 11 years accept DELNA and believe it is a fair assessment of their language skills (see Figure 3). However, as has been shown, not all who score low on the Diagnosis phase meet with the Language Adviser and get the advice they need. In spite of this, they acknowledge the difficulties they experience because of their lack of English proficiency. 


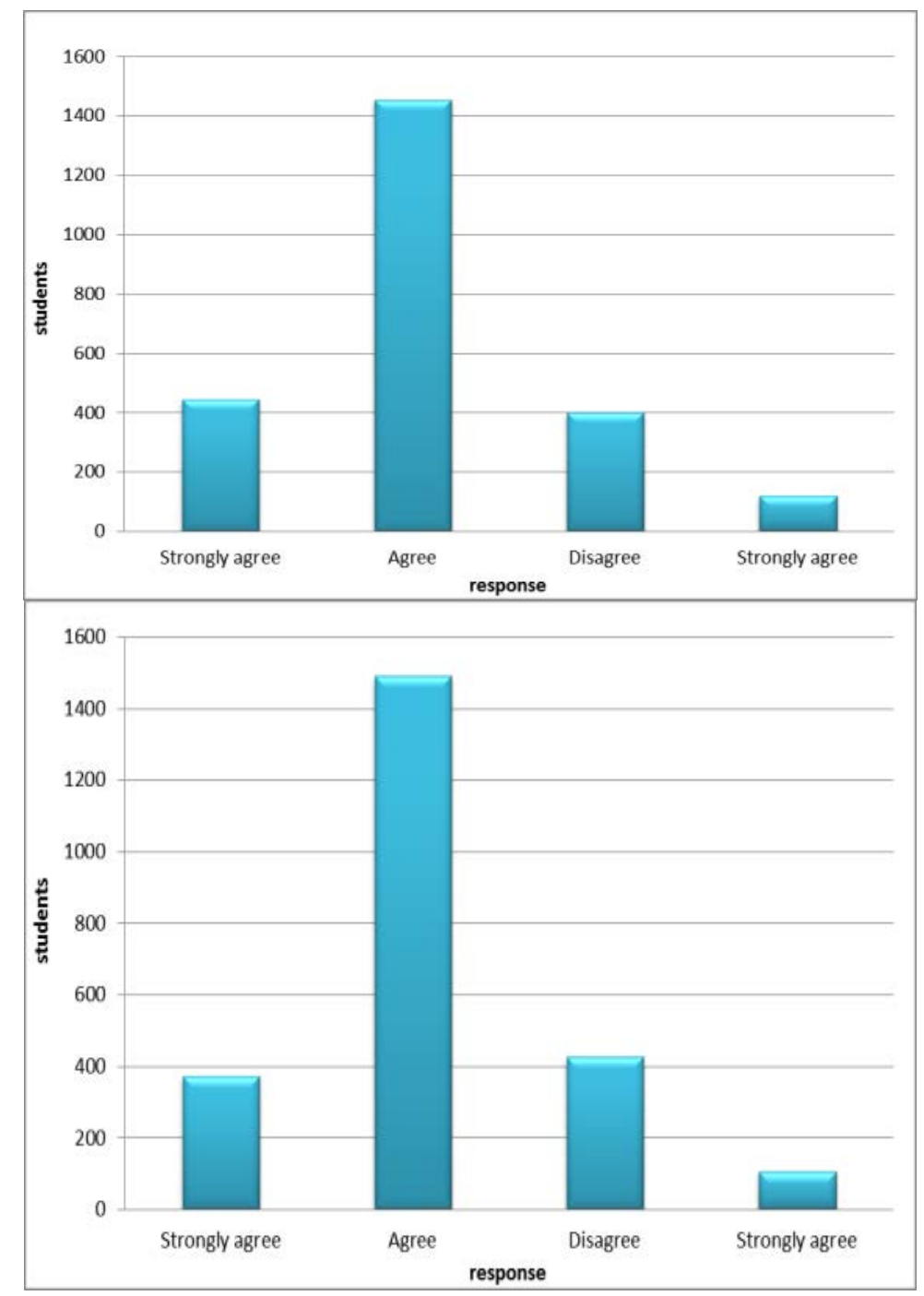

Figure 3. Responses to the questionnaire items: 'I was happy to do DELNA' and 'DELNA is a fair assessment of my English ability’

A relevant question in the evaluation questionnaire, "How difficult have you found the English language demands of different activities in your course of study?”, has elicited the responses collated in Figure 4. Although a large proportion of the responses suggest that most of these study situations were relatively easy to cope with, the prominence of responses in the "Neutral" category indicates a considerable amount of ambivalence. It should be noted again that completion of the online questionnaire is voluntary and students who were really struggling with their courses were undoubtedly under-represented. As would be expected, writing at university was the skill that many found most difficult, followed by taking lecture notes, participating in tutorials and reading academic texts. 


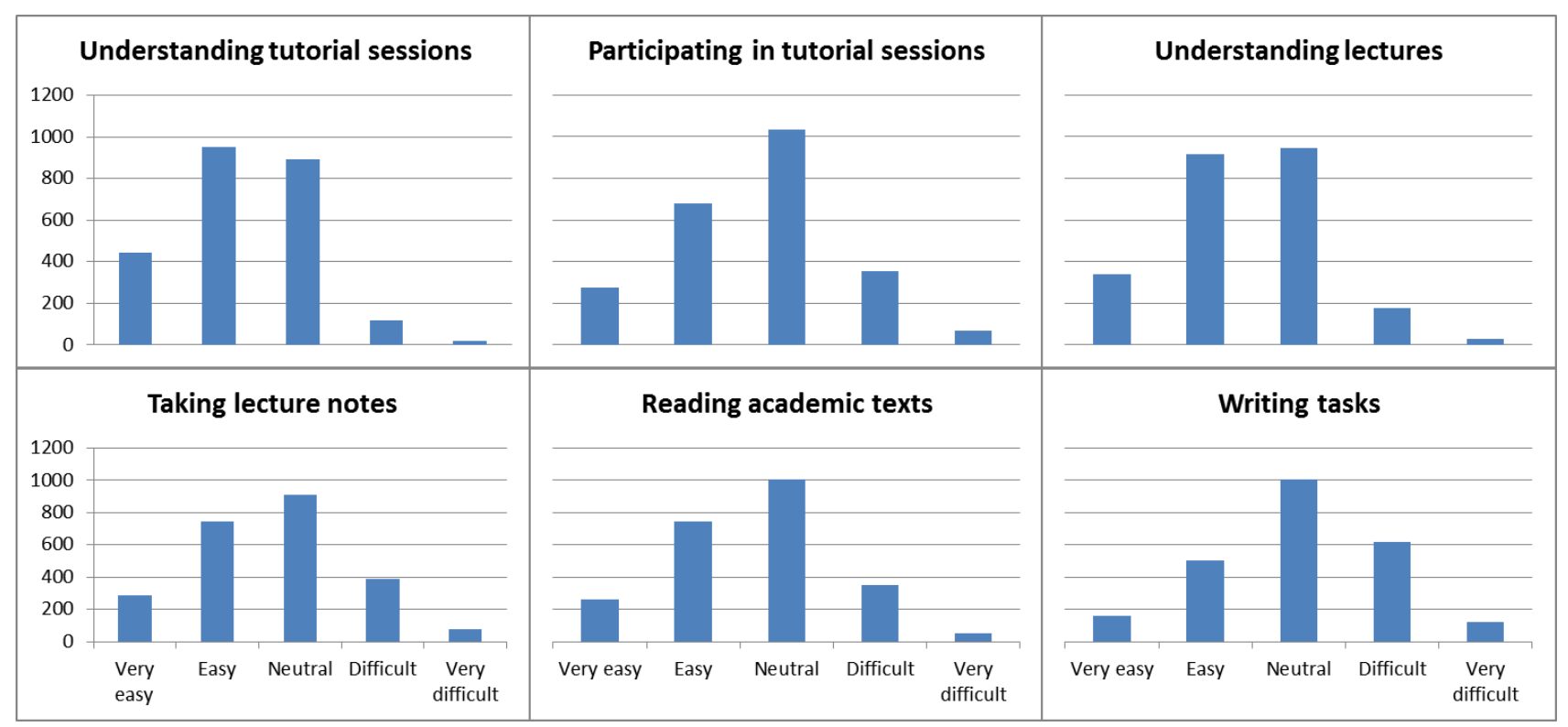

Figure 4. Responses to questionnaire items about coping with English demands in various situations

\subsection{Raising staff awareness of language needs}

The language difficulties the students have identified as being most significant are reported by DELNA staff within the University through the DELNA Reference Group, through presentations at Teaching and Learning Showcases, and at faculty meetings so that staff can adapt their teaching methods accordingly. It has, however, been suggested that some academics are irritated by students' lack of language proficiency (Arkoudis, Baik \& Richardson, 2012; Murray, 2010) and some students have sensed that irritation:

I am still not confident to speak with native speakers. The worst is when I asked a lecturer a question, his answer is, "You had better improve your English before asking me question.” (2010)

Academics who know nothing of second language acquisition may think that there is some "quick fix" (Arkoudis et al., 2012; Murray, 2010), and that a short course will have students "quickly returning to classes ready to learn the disciplinary content" (Channock, 2007, quoted in Arkoudis et al., 2012: 43). Students from English-speaking backgrounds generally develop their academic literacy independently as they study, whereas EAL students often need to develop their language proficiency as a prerequisite to acquiring academic literacy in their particular disciplinary areas of study.

\subsection{Courses and self-study programmes}

The courses and other structured study programmes that are available at the University to address students' academic language needs are offered in varied formats and contexts: 
- Since 2001 the Department of Applied Language Studies and Linguistics (DALSL) has offered credit courses in academic listening, reading and writing, and more recently, speaking. The courses had the subject name ESOL (English for Speakers of Other Languages) and were perceived to be largely for international students. However, in recent years it has been recognised that Pasifika students and others from migrant backgrounds who were primarily speakers of English could benefit from the courses and thus, in order to encourage such students to enrol, the subject name has been changed to Academic English. The Department also offers a more advanced course in English Writing for students with a higher level of proficiency in the language.

- An English Department course on academic writing and one on scientific communication taught by the Science Faculty are available for the General Education programme, which all undergraduate students must take part in during their first two years of study.

- For many years, the Business School has provided support for its first-year EAL students by employing tutors to run discipline-specific tutorials with a language focus. Various models have been implemented, ranging from adjunct and voluntary to embedded and compulsory. Internal evaluations have shown that students taking advantage of the tutorials have had more successful academic outcomes than those who avoided them (Eberhard \& Lindberg, 2010).

- The Faculty of Engineering and the Schools of Nursing and Pharmacy have created a special course code which does not carry any academic credit but is a compulsory component of the first year of study for students who have not met the minimum DELNA requirement. The DELNA Language Adviser introduces the students to a self-study programme which includes a ten-hour online course, language exercises to be completed, an advisory session at the English Language Enrichment centre, oral activities (in the case of Nursing and Pharmacy), and an exit test.

- At the Faculty of Education, their own team of language advisers meet with students after the DELNA Diagnosis. The students are given an individual learning plan, which includes accessing web-based materials and reflecting on their learning in an online journal. Their progress is assessed by an exit test later in the year. Students who avoid this requirement are barred from being posted to a school for the first-year teaching practicum.

- In the case of doctoral students, there is a wider range of language enhancement options, depending on their faculty and their DELNA results profile. The DELNA Language Adviser makes recommendations which are communicated to the Graduate Centre and the student's supervisor, as well as the student. The recommendations include language and study skills workshops, online resources and discussion sessions. 
Some students are required to take a credit course, with a minimum passing grade specified. The students must keep a record of their activities during the year, which is reviewed by the head of the English Language Enrichment centre and the Graduate centre before the provisional registration can be confirmed.

\subsection{Other language enrichment options}

Apart from the credit courses and the tailored programmes for English language enhancement that we have already described, there are two more generic services available on campus. One is Student Learning Services (SL), which employs a team of learning advisers and tutors to run workshops, conduct individual tutorials and provide online resources for students, particularly in the areas of academic writing and study skills. The other service, which was originally the English Language Self-Access Centre (ELSAC), is now known as English Language Enrichment (ELE), and it offers more specialised assistance to EAL students by means of a collection of print and web-based materials, individual consultations on academic writing, and informal sessions to promote oral fluency called “Let's Talk!” From 2013, the two units have been incorporated with the University libraries into an integrated department of Libraries and Learning Services. This move is in keeping with a recent response to the DELNA online evaluation questionnaire:

I find ELSAC is a really helpful place and there are many useful resources to get my English improving. But if it is known by more people, the resources can be more efficiently used. Probably, combining some language workshops in ELSAC and SLC, having more cooperations between them could help people get to know them better. (2010)

More generally, the questionnaire elicits comments about the services provided by SL and ELE, giving useful feedback both to the staff of these units and to the DELNA Language Adviser:

Yes, I thought that when I just come from Iran here, I just think that my English will be magically better - with just being in an English country speaking. But it is not magicking! (2011)

I find out that doing the online task help me improve my academic writing. I know that I still need practice on my writing, to get perfect grammar for assignment writing. still small grammar mistakes but online [ELE] helps me a lot. (2011)

I learnt a lot for ELE online studying and got very useful feedback from my language advisor. (2012)

Two recent developments in the Student Learning programme can be seen as responding to student feedback. One is a greater emphasis on support for the development of students' speaking skills, which have often been seen as having a lower priority than the 
enhancement of academic literacy (interpreted as reading and writing). The "Let's Talk!" sessions at ELE represent one response:

I really really want to improve my spoken English. I found going to "Let's talk" in ELSAC pretty useful. However, besides going to this program, I cannot find another to practice my spoken English. (2010)

In addition, on a more formal basis the Department of Applied Language Studies and Linguistics has added to its Academic English programme credit courses on academic presentations and academic seminar discussion.

The second development is a closer collaboration between language tutors in Student Learning and teaching staff in particular disciplines also reflected in this longstanding request:

More tutors that have the same background area of study, e.g. a tutor who has studied sociology will be more helpful to a student who is currently studying sociology as they will be more helpful in terms of essay assistance. (2003)

\section{CONCLUSION}

University students develop their academic literacy as they study, and it is expected that those who complete the DELNA Screening successfully will do so independently. Others, particularly those identified by the DELNA Diagnosis as being at risk, will need considerable assistance, if not formal instruction in taught courses, to meet the literacy demands of their degree studies. By identifying the latter students and guiding them to the language enrichment that enables them to begin this process, DELNA plays an important role in meeting the University's perceived responsibility to address the academic language needs of the students that it admits.

In their questionnaire responses or in interviews students have often described DELNA as the "wake-up call” they needed to recognise their language needs. This has applied particularly to international students who have "passed" a proficiency test such as IELTS, and to EAL students who have met the literacy requirement for matriculation from secondary school. Students from migrant language backgrounds whose fluent oral communication skills in English identify them as New Zealanders are generally unaware that they are inadequately prepared for university study; they are often surprised or indeed upset when they are asked to take the Diagnosis and meet with a language adviser. However, their questionnaire responses and emails to the language advisers often express gratitude for the personal guidance that has helped them cope as new undergraduates.

As this paper has shown, DELNA has made an impact at the University over the past 11 years. It has become embedded as part of the process of being admitted to the institution, as evidenced by the numbers of students taking the Screening. Acceptance of the programme has 
come about through the changes made to its composition and administration and to the delivery of effective English language programmes. The development of the two-tiered assessment and the online delivery of the Screening was a turning point in increasing student uptake. This allowed proficient students to be efficiently exempted from further assessment, so that resources could be concentrated on identifying students at real risk of underachievement. The appointment of DELNA Language Advisers was also a crucial step in guiding students to appropriate forms of language support to enhance their chance of success. The explanation of their results in a personal interview, something the first DELNA candidates missed, prepares students well both cognitively and affectively for further language development. The fact that considerable numbers of students still avoid the postDiagnosis advisory session is an ongoing challenge. Although it has been DELNA's philosophy that students will benefit most from language enrichment if they are personally motivated to take it up, experience has shown that some pressure is also needed.

Auckland is unusual, if not unique, among universities in Australia and New Zealand in the comprehensiveness of its programme for post-entry language assessment. There are several factors that help to explain its relative success:

- the need to accommodate the relevant provisions in New Zealand education law, which discouraged the targeting of particular groups within the student body;

- a high level of commitment by senior management, including ongoing central funding and a policy of implementing the programme across the whole institution;

- the availability of expertise in language assessment and English for academic purposes, both within the university and through close links with the Language Testing Research Centre at the University of Melbourne;

- and, not least, the efforts of a small dedicated staff who have tirelessly promoted DELNA and drawn on the skills of a whole network of people to add to the quality of the programme.

As we have emphasised in this paper, another key element has been the focus on presenting the assessment to the students in a positive manner, and just as importantly, responding to their feedback in ways that have enhanced the acceptability of the programme in their eyes. This gives new vigour and purpose to the concept of face validity.

The assessment is of course not an end in itself, and its effectiveness should be judged by its impact on the academic literacy of each succeeding cohort of incoming students and, ultimately, the students' academic achievement in their degree studies. In this regard, the various programmes to support the students in enhancing their academic language ability have a crucial role to play. The Auckland model is not the only viable form of post-entry language assessment; its very comprehensiveness requires a generic approach to academic reading and writing which has been criticised by Arkoudis et al. (2012) in the Australian context as not representing the discipline-specific nature of academic literacy (or literacies). These authors would favour the more embedded strategy embodied in the University of Sydney's Measuring 
the Academic Skills of University Students (MASUS) procedure (Bonanno \& Jones, 2007), which requires the active involvement of the teaching staff of particular academic programmes in the design of the assessment and in follow-up action within their own courses. Nevertheless, the University of Auckland is moving towards a mixed model of English language enhancement, with embedded support in particular professional degree programmes and a more generic approach elsewhere, which seeks an optimum balance between compulsion to complete the assessment and a measure of autonomy for the students in determining how (or whether) to enhance their academic language ability.

\section{REFERENCES}

Alderson, J.C., Clapham, C., \& Wall, D. (1995). Language Test Construction and Evaluation. Cambridge: Cambridge University Press.

Arkoudis, S., Baik, C., \& Richardson, S. (2012). English language standards in higher education: From entry to exit. Camberwell, Australia: ACER Press.

AUQA (Australian Universities Quality Agency) (2009). Good Practice Principles for English language proficiency for international students in Australian universities, Report to the Department of Education, Employment and Workplace Relations, Canberra. Retrieved from http://www.auqa.edu.au/files/otherpublications/good\%20practice\%20principles\%20for\%20engl ish\%20language\%20proficiency\%20report.pdf

Bachman, L.F. (1990). Fundamental Considerations in Language Testing. Oxford: Oxford University Press.

Bachman, L.F., \& Palmer, A.S. (1996). Language Testing in Practice. Oxford: Oxford University Press.

Birrell, B. (2006). Implications of low English standards among overseas students at Australian universities. People and Place, 14, 53-64. Melbourne: Centre for Population and Urban Research, Monash University.

Bonanno, H., \& Jones, J. (2007). The MASUS procedure: Measuring the Academic Skills of University Students. A resource document. Sydney: Learning Centre, University of Sydney. Retrieved from http://sydney.edu.au/stuserv/documents/learning_centre/MASUS.pdf.

Carroll, B.J. (1980). Testing Communicative Performance. Oxford: Pergamon.

Davies, A. (1990). Principles of Language Testing. Oxford: Blackwell.

Davies, A., Brown, A., Elder, C., Hill, K., Lumley, T., \& McNamara, T. (1999). Dictionary of Language Testing. Cambridge: Cambridge University Press.

Davies, A., \& Elder, C. (2005). Validity and validation in language testing. In E. Hinkel (Ed.), Handbook of Research in Second Language Teaching and Learning (pp. 795-813). Mahwah, NJ.: Lawrence Erlbaum.

Dunworth, K. (2009). An investigation into post-entry English language assessment in Australian universities. Journal of Academic Language and Learning, 3, 1-13.

Eberhard, A., \& Lindberg, L. (2010). Treats, trials and tribulations. Discipline-centred language support: Towards the ideal. Paper presented at the $10^{\text {th }}$ Annual Teaching and Learning Showcase. Centre for Academic Development, University of Auckland.

Elder, C., Barkhuizen, G., Knoch, U., \& von Randow, J. (2007). Evaluating rater responses to an online training program for writing assessment. Language Testing, 24, 1-28.

Elder, C., \& Erlam, R. (2001). Development and validation of the Diagnostic English Language Needs Assessment (DELNA). Unpublished final project report. Department of Applied Language Studies and Linguistics, University of Auckland. 
Elder, C., Knoch, U., Barkhuizen, G., \& von Randow, J. (2005). Feedback to enhance rater training: Does it work? Language Assessment Quarterly, 2, 175-196.

Elder, C., McNamara, T., \& Congdon, P. (2003). Rasch techniques for detecting bias in performance assessments: an example comparing the performance of native and non-native speakers on a test of academic English. Journal of Applied Measurement, 4, 181-197.

Elder, C., \& von Randow, J. (2002). Report on the 2002 pilot of DELNA at the University of Auckland. Unpublished research report. University of Auckland.

Elder, C., \& von Randow, J. (2008). Exploring the utility of a web-based English language screening tool. Language Assessment Quarterly, 5, 173-194.

Ellis, R., \& Hattie, J. (1999). English language proficiency at the University of Auckland: A proposal. Unpublished paper. University of Auckland.

Knoch, U. (2009). The development and validation of a rating scale for diagnostic writing assessment. Language Testing, 26, 275-304.

Knoch, U. (2012). At the intersection of language assessment and academic advising: Communicating results of a large-scale diagnostic academic English writing assessment to students and other stakeholders. Papers in Language Testing and Assessment, 1, 31-49.

Knoch, U., Read, J., \& von Randow, J. (2007).Re-training writing raters online: How does it compare with face-to-face training? Assessing Writing, 12, 26-43.

Lado, R. (1961). Language Testing. London: Longman.

Lane, B. (2012, August 22). National regulator sharpens focus on English language standards. The Australian. Retrieved from http://www.theaustralian.com.au/higher-education/nationalregulator-sharpens-focus-on-english-language-standards/story-e6frgcjx-1226455260799.

Manning, W.H. (1987). Development of cloze-elide tests of English as a second language. TOEFL Research Reports, No. 23. Princeton, NJ: Educational Testing Service.

Moran, T. (1995). Report of the Sub-Committee on English Language and Entrance. Unpublished report. University of Auckland.

Murray, N. (2010). Considerations in the post-enrolment assessment of English language proficiency: Reflections from the Australian context. Language Assessment Quarterly, 7, 343-358.

Ransom, L. (2009). Implementing the post-entry English language assessment policy at the University of Melbourne: Rationale, processes and outcomes. Journal of Academic Language and Learning, 3, 13-25.

Read, J. (2008). Identifying academic language needs through diagnostic assessment. Journal of English for Academic Purposes, 7, 180-190.

Read, J. (forthcoming). Issues in post-entry language assessment in English-medium universities. Language Teaching. Available on Cambridge Journals Online 2013 doi:10.1017/S0261444813000190.

Read, J., \& Chapelle, C.A. (2001). A framework for second language vocabulary assessment. Language Testing, 18, 1-32. 